\title{
Shelter from the Storm: Trauma-Informed Care in Homelessness Services Settings
}

\author{
Elizabeth K. Hopper ${ }^{*}, 1$, Ellen L. Bassuk ${ }^{2,3}$, and Jeffrey Olivet ${ }^{4}$ \\ ${ }^{I}$ The Trauma Center at JRI 1269 Beacon Street Brookline, MA 02446, USA \\ ${ }^{2}$ The National Center on Family Homelessness, 181 Wells Avenue, Newton, MA 02459, USA \\ ${ }^{3}$ Department of Psychiatry, Harvard Medical School, USA \\ ${ }^{4}$ Centre for Social Innovation 215 Spadina Avenue, Suite 120 Toronto, Ontario M5T 2C7, Canada
}

\begin{abstract}
It is reasonable to assume that individuals and families who are homeless have been exposed to trauma. Research has shown that individuals who are homeless are likely to have experienced some form of previous trauma; homelessness itself can be viewed as a traumatic experience; and being homeless increases the risk of further victimization and retraumatization. Historically, homeless service settings have provided care to traumatized people without directly acknowledging or addressing the impact of trauma. As the field advances, providers in homeless service settings are beginning to realize the opportunity that they have to not only respond to the immediate crisis of homelessness, but to also contribute to the longer-term healing of these individuals. Trauma-Informed Care (TIC) offers a framework for providing services to traumatized individuals within a variety of service settings, including homelessness service settings. Although many providers have an emerging awareness of the potential importance of TIC in homeless services, the meaning of TIC remains murky, and the mechanisms for systems change using this framework are poorly defined. This paper explores the evidence base for TIC within homelessness service settings, including a review of quantitative and qualitative studies and other supporting literature. The authors clarify the definition of Trauma-Informed Care, discuss what is known about TIC based on an extensive literature review, review case examples of programs implementing TIC, and discuss implications for practice, programming, policy, and research.
\end{abstract}

Keywords: Homelessness, trauma, trauma-informed, systems change.

\section{INTRODUCTION}

\section{Trauma-Informed Care: A Paradigm Shift for Homeless Services}

\begin{abstract}
"Homelessness deprives individuals of ...basic needs, exposing them to risky, unpredictable environments. In short, homelessness is more than the absence of physical shelter, it is a stress-filled, dehumanizing, dangerous circumstance in which individuals are at high risk of being witness to or victims of a wide range of violent events" [1].
\end{abstract}

Homelessness is a traumatic experience. Individuals and families experiencing homelessness are under constant stress, unsure of whether they will be able to sleep in a safe environment or obtain a decent meal. They often lack a stable home and also the financial resources, life skills, and social supports to change their circumstances. In addition to the experience of being homeless, an overwhelming percentage of homeless individuals, families, and children have been exposed to additional forms of trauma, including: neglect, psychological abuse, physical abuse, and sexual abuse during childhood; community violence; combat-related

*Address correspondence to this author at the Trauma Center at JRI 1269, Beacon Street Brookline, MA 02446, USA; Tel: (617) 232-1303, Ext. 211; E-mail: ehopper@jri.org trauma; domestic violence; accidents; and disasters. Trauma is widespread and affects people of every gender, age, race, sexual orientation, and background within homeless service settings.

Early developmental trauma-including child abuse, neglect, and disrupted attachment-provides a subtext for the narrative of many people's pathways to homelessness [2]. Violence continues into adulthood for many people, with abuse such as domestic violence often precipitating homelessness [3-5], and with homelessness leaving people vulnerable to further victimization. The impact of traumatic stress often makes it difficult for people experiencing homelessness to cope with the innumerable obstacles they face in the process of exiting homelessness [6], and the victimization associated with repeated episodes of homelessness. Research has found that people who experienced repeated homelessness were more likely than people with a single episode of homelessness to have been abused, often during childhood [6].

Trauma refers to an experience that creates a sense of fear, helplessness, or horror, and overwhelms a person's resources for coping. The impact of traumatic stress can be devastating and long-lasting, interfering with a person's sense of safety, ability to self-regulate, sense of self, perception of control and self-efficacy, and interpersonal relationships. Some people have minimal symptoms after trauma exposure or recover quickly, while others may 
develop more significant and longer-lasting problems such as Posttraumatic Stress Disorder (PTSD) and Complex Trauma.

Trauma reactions are not the only psychiatric issue facing people who are homeless; many people experiencing homelessness also suffer from depression, substance abuse [710], and severe mental illness $[8,10]$. These issues leave individuals even more vulnerable to revictimization [11], interfere with their ability to work, impair their social networks [8], and further complicate their service needs.

These findings suggest that we will be unable to solve the issue of homelessness without addressing the underlying trauma that is so intricately interwoven with the experience of homelessness. Those working in homeless services have the opportunity to reach many trauma survivors who are otherwise overlooked. Providers in these settings address the immediate crisis by offering food, shelter, and clothing; but they can also contribute to longer-lasting changes by helping an individual or family develop supportive connections in the community and begin to heal from past traumas. Despite this fact, few programs serving homeless individuals and families directly address the specialized needs of trauma survivors. Homeless services have a long history of serving trauma survivors, without being aware of or addressing the impact of traumatic stress [12]. Overwhelmed by the daily needs of their clients, providers in these settings often have few resources to address issues of long-term recovery.

With increasing recognition of the pervasiveness of traumatic stress among people experiencing homelessness, awareness is growing of the importance of creating TraumaInformed Care within homeless services settings. TraumaInformed Care (TIC) involves "understanding, anticipating, and responding to the issues, expectations, and special needs that a person who has been victimized may have in a particular setting or service. At a minimum, trauma-informed services endeavor to do no harm - to avoid retraumatizing or blaming [clients] for their efforts to manage their traumatic reactions" [13]. Implementing TIC requires a philosophical and cultural shift within an agency, with an organizational commitment to understanding traumatic stress and to developing strategies for responding to the complex needs of survivors.

Despite its importance, the implementation of TIC within homelessness service settings is still in its infancy. Currently, the nature of TIC remains ill-defined. Strategies for implementation are obscure, few program models exist, and there is limited communication and collaboration among programs implementing TIC. The descriptive and research literature in this area is sparse, with only a handful of studies examining the nature and impact of TIC. More clarification is needed about what exactly defines TIC, what changes should be made within systems wishing to offer TIC, and how these changes should be implemented.

The purpose of this paper is to review the evidence base that supports the use of TIC for individuals and families experiencing homelessness. In this review, we have attempted to:

- $\quad$ Establish a consensus-based definition of TIC

- Discuss what is known about TIC based on our literature review
- Describe models and case examples of what is being done in the field to implement TIC within homeless service settings

We conclude by summarizing implications of our current state of knowledge for practice, programming, policy, and research and by highlighting next steps for developing evidence-based, trauma-informed homeless services.

\section{What is Trauma-Informed Care (TIC)?}

What is meant by TIC? Although there is agreement that "trauma-informed" refers generally to a philosophical/ cultural stance that integrates awareness and understanding of trauma, there is no consensus on a definition that clearly explains the nature of TIC.

TIC supports the delivery of Trauma-Specific Services (TSS). TSS refers to interventions that are designed to directly address the impact of trauma, with the goals of decreasing symptoms and facilitating recovery. TSS differs from TIC, in that TSS are specific treatments for mental disorders resulting from trauma exposure, while TIC is an overarching framework that emphasizes the impact of trauma and that guides the general organization and behavior of an entire system. TSS may be offered within a trauma-informed program or as stand-alone services [12].

Based on the literature review, we summarized the basic principles of TIC proposed by various workgroups, organizations, expert panels, and researchers. (see Table 1). Each of these sources posited a unique definition of TIC. We identified and highlighted common cross-cutting themes and then synthesized them into a single definition. Themes include:

- Trauma awareness: Trauma-informed service providers incorporate an understanding of trauma into their work. This may involve altering staff perspectives, with providers understanding how various symptoms and behaviors represent adaptations to traumatic experiences. Staff training, consultation, and supervision are important aspects of organizational change towards TIC and organizational practices should be modified to incorporate awareness of the potentially devastating impact of trauma. For example, agencies may implement routine screening for histories of traumatic exposure, may conduct routine assessments of safety, and may develop strategies for increasing access to traumaspecific services. Dealing with vicarious trauma and self-care is also an essential ingredient of traumainformed services. Many providers have experienced trauma themselves and may be triggered by client responses and behaviors.

- Emphasis on safety: Because trauma survivors often feel unsafe and may actually be in danger (e.g., victims of domestic violence), TIC works towards building physical and emotional safety for consumers and providers. Precautions should be taken to ensure the physical safety of all residents. In addition, the organization should be aware of potential triggers for consumers and strive to avoid retraumatization. Because interpersonal trauma often involves boundary violations and abuse of power, systems that are aware of trauma dynamics should establish clear roles and boundaries that are an outgrowth of collaborative decision-making. 
Privacy, confidentiality, and mutual respect are also important aspects of developing an emotionally safe atmosphere. Additionally, cultural differences and diversity (e.g., gender, ethnicity, sexual orientation) must be addressed and respected within trauma-informed settings.

- Opportunities to rebuild control: Because control is often taken away in traumatic situations, and because homelessness itself is disempowering, traumainformed homeless services emphasize the importance of choice for consumers. They create predictable environments that allow consumers to rebuild a sense of efficacy and personal control over their lives. This includes involving consumers in the design and evaluation of services.

-

Strengths-based approach: Finally, TIC is strengths-based, rather than deficit-oriented. These service settings assist consumers to identify their own strengths and develop coping skills. TIC service settings are focused on the future and utilize skillsbuilding to further develop resiliency.

These principles form a standard for programs wishing to develop TIC within homeless service settings. Based on these combined principles, we developed a consensus-based definition of TIC:

\section{Consensus-Based Definition}

\begin{abstract}
"Trauma-Informed Care is a strengths-based framework that is grounded in an understanding of and responsiveness to the impact of trauma, that emphasizes physical, psychological, and emotional safety for both providers and survivors, and that creates opportunities for survivors to rebuild a sense of control and empowerment."
\end{abstract}

Trauma-informed approaches are designed to respond to the impact of trauma. The principles described above target the specialized needs of trauma survivors and describe how services can be delivered through the lens of trauma.

\section{METHODS}

This paper reviews the evidence base supporting the effectiveness of TIC for people experiencing homelessness. To date, most determinations of what constitutes evidence-based practice have relied on outcome-based quantitative research. However, this approach neglects qualitative analyses that examine the nature and process of the intervention, as well as a wealth of information that reflects what is occurring in practice. In fact, corroborative evidence, including clinical wisdom about "what works," is often the starting point for developing both qualitative and quantitative studies. In the homelessness field, corroborative evidence may be the primary body of knowledge we have about a particular intervention.

For this review, we utilized a comprehensive framework that was developed by the Homelessness Resource Center (HRC) for assessing the level of evidence of an emerging, promising or best practice [15]. The goal of this framework is not to decide whether a practice qualifies as evidence-based, but rather to synthesize all that we currently know about the intervention. Thus, our review included peer-reviewed quantitative and qualitative studies, as well as corroborative literature (e.g., program evaluations and unpublished pilot studies).

The literature on TIC is significantly greater in mental health and substance use fields than within the homelessness field. Thus, we also reviewed the current evidence base for traumainformed practices in these areas since there is a large overlap in the difficulties faced by many individuals with mental health/substance use issues and those in homeless service settings. In fact, in the Women, Co-Occurring Disorders, and Violence Study (WCDVS), a large multi-site study examining trauma-informed services for women with co-occurring disorders and trauma exposure, $70.4 \%$ of participants had been homeless at some point in their lives [16]. We reviewed evidence for trauma-informed services within all these settings, applying this broader knowledge base to our understanding of TIC within homeless service settings.

We conducted our literature review by searching two databases, PsycInfo and Medline (PubMed), for peer-reviewed articles published in major journals. In addition, we used the Google search engine to locate web-based literature and program information. Our search terms included: homeless, homelessness, housing, shelters, trauma, trauma-informed, PTSD, services, abuse, violence, domestic violence, psychological, substance use, and mental health. We also completed more specialized searches on unique populations (using search terms such as youth, men, ethnicity, veterans), authors of note (e.g., Harris, Fallot, Bassuk, and van der Kolk), models (e.g., Attachment, Self-Regulation and Competency [ARC] and Sanctuary), programs (e.g., Community Connections, the STAR program, and the Community Trauma Treatment Center for Runaway and Homeless Youth), and research studies (e.g., the Women, Co-Occurring Disorders, and Violence Study).

In addition to reviewing the literature, we contacted various programs directly, by telephone or email, including: the National Center on Family Homelessness (Moses, Guarino); Homelessness Resource Center (Olivet); Community Connections (Fallot); the Institute for Health and Recovery (Markoff \& Dargon-Hart); CT State Department of Mental Health and Addiction Services (Leal); the Domestic Violence \& Mental Health Policy Initiative (Brashler, Hall); the Community Trauma Treatment Center for Runaway and Homeless Youth (Schneir); the Trauma Center at JRI/ Youth on Fire, developers of Phoenix Rising (Spinazzola); Kinniburgh and Blaustein, developers of ARC; Cincinnati Children's Hospital Medical Center, developers of CARE (Pearl); University of Connecticut Department of Psychology and the CT Department of Mental Health and Addiction Services Research Division (Marra). Many of these programs sent unpublished program evaluation reports, manuals, or self-assessment tools, for inclusion in this review.

\section{RESULTS}

\section{Organizational Needs Assessments: Do We Need Trauma-Informed Care?}

Needs assessments can be used to identify needs and to detect gaps in service within a system. We began by reviewing results of needs assessments conducted by several agencies regarding the relevance of trauma within their service system and the need for TIC. These needs 
Table 1. Principles of Trauma-Informed Care

\begin{tabular}{|c|c|c|c|c|c|c|}
\hline \multirow{2}{*}{\multicolumn{2}{|c|}{$\begin{array}{c}\text { Common Principles Across } \\
\text { Definitions }\end{array}$}} & \multicolumn{5}{|c|}{ Example Definitions of Trauma-Informed Care } \\
\hline & & \begin{tabular}{|l} 
Community \\
Connections: Five \\
Guiding Principles for \\
Trauma-Informed \\
Services [12]
\end{tabular} & $\begin{array}{l}\text { NASMHPD*: Criteria } \\
\text { for Building a Trauma- } \\
\text { Informed Mental } \\
\text { Health Service System }\end{array}$ & $\begin{array}{l}\text { NCTSN**: } \\
\text { Principles of } \\
\text { Trauma-Informed } \\
\text { Care for Children }\end{array}$ & $\begin{array}{l}\text { NCFH***: } \\
\text { Operating } \\
\text { Principles for } \\
\text { Trauma- } \\
\text { Informed } \\
\text { Organizational } \\
\text { Self- } \\
\text { Assessment }\end{array}$ & $\begin{array}{l}\text { WCDVS } * * * * \\
\text { Trauma-Informed } \\
\text { or Trauma- } \\
\text { Denied: Principles } \\
\text { \& Implementation } \\
\text { of Trauma- } \\
\text { Informed Services } \\
\text { for Women [14]. }\end{array}$ \\
\hline \multicolumn{2}{|c|}{$\begin{array}{c}\text { Consensus-Based Principles } \\
\text { Across Definitions }\end{array}$} & Theory-Based & Expert Trauma Panel & Experts & Theory-Based & Research-based \\
\hline \multirow[t]{4}{*}{$\begin{array}{l}\text { 1. Trauma } \\
\text { Awareness }\end{array}$} & $\begin{array}{l}\text { a. Program } \\
\text { philosophy and } \\
\text { mission }\end{array}$ & & $\begin{array}{l}\text { Trauma function/ focus, } \\
\text { trauma policy or } \\
\text { position, financing for } \\
\text { best practices, trauma- } \\
\text { informed services, } \\
\text { clinical practice } \\
\text { guidelines for people } \\
\text { with trauma histories, } \\
\text { trauma-informed disaster } \\
\text { planning, systems } \\
\text { integration, research \& } \\
\text { data on trauma \& } \\
\text { evidence-based \& best- } \\
\text { practice treatment } \\
\text { models, access to } \\
\text { evidence-based \& best- } \\
\text { practice trauma treatment }\end{array}$ & & $\begin{array}{l}\text { Trauma } \\
\text { awareness; } \\
\text { basic } \\
\text { understanding } \\
\text { of trauma \& } \\
\text { triggers; } \\
\text { includes staff } \\
\text { training \& } \\
\text { supervision, } \\
\text { educating } \\
\text { consumers } \\
\text { about trauma }\end{array}$ & $\begin{array}{l}\text { Recognize the } \\
\text { impact of trauma on } \\
\text { development and } \\
\text { coping }\end{array}$ \\
\hline & $\begin{array}{l}\text { b. Staff } \\
\text { education, } \\
\text { training, and } \\
\text { consultation }\end{array}$ & & $\begin{array}{l}\text { Workforce orientation, } \\
\text { training, support, } \\
\text { competencies and job } \\
\text { standards related to } \\
\text { trauma; promote } \\
\text { education of } \\
\text { professionals in trauma }\end{array}$ & & & $\begin{array}{l}\text { Emphasize trauma } \\
\text { recovery as a } \\
\text { primary goal }\end{array}$ \\
\hline & c. Practices & & $\begin{array}{l}\text { Trauma screening and } \\
\text { assessment; Trauma- } \\
\text { specific services, } \\
\text { including evidence-based } \\
\text { and emerging best- } \\
\text { practice treatment } \\
\text { models }\end{array}$ & & $\begin{array}{l}\text { Integration } \\
\text { (symptoms } \\
\text { such as } \\
\text { adaptive } \\
\text { coping, } \\
\text { integrating } \\
\text { services, } \\
\text { trauma-specific } \\
\text { services) }\end{array}$ & \\
\hline & $\begin{array}{l}\text { d. Recognition of } \\
\text { vicarious trauma } \\
\text { and staff self- } \\
\text { care }\end{array}$ & & & & & \\
\hline \multirow[t]{3}{*}{ 2. Safety } & $\begin{array}{l}\text { a. Physical and } \\
\text { emotional safety }\end{array}$ & $\begin{array}{l}\text { Safety (physical and } \\
\text { emotional) }\end{array}$ & & $\begin{array}{l}\text { Maintaining clear } \\
\text { and consistent } \\
\text { boundaries }\end{array}$ & $\begin{array}{l}\text { Safety, basic } \\
\text { needs, } \\
\text { consistency, } \\
\text { and } \\
\text { predictability }\end{array}$ & $\begin{array}{l}\text { Create an } \\
\text { atmosphere of } \\
\text { safety, respect, and } \\
\text { acceptance }\end{array}$ \\
\hline & $\begin{array}{l}\text { b. Relationships: } \\
\text { authentic, } \\
\text { respectful, clear } \\
\text { boundaries }\end{array}$ & $\begin{array}{l}\text { Trustworthiness (clear } \\
\text { tasks, consistent } \\
\text { practices, staff-consumer } \\
\text { boundaries) }\end{array}$ & & $\begin{array}{l}\text { [see Delivering } \\
\text { services below] }\end{array}$ & $\begin{array}{l}\text { Engagement: } \\
\text { respectful } \\
\text { nonjudgmental } \\
\text { relationships, } \\
\text { clear } \\
\text { boundaries }\end{array}$ & $\begin{array}{l}\text { Utilize a relational } \\
\text { collaboration model. } \\
\text { Growth is fostered } \\
\text { by mutual, } \\
\text { respectful, authentic } \\
\text { relationships }\end{array}$ \\
\hline & $\begin{array}{l}\text { c. Avoid } \\
\text { retraumatization }\end{array}$ & & $\begin{array}{l}\text { Procedures avoid } \\
\text { retraumatization and } \\
\text { reduce impacts of trauma }\end{array}$ & & & $\begin{array}{l}\text { Minimize } \\
\text { retraumatization }\end{array}$ \\
\hline
\end{tabular}


(Table 1) contd....

\begin{tabular}{|c|c|c|c|c|c|c|}
\hline \multicolumn{2}{|c|}{$\begin{array}{c}\text { Consensus-Based Principles } \\
\text { Across Definitions }\end{array}$} & Theory-Based & Expert Trauma Panel & Experts & Theory-Based & Research-based \\
\hline & $\begin{array}{l}\text { d. Acceptance } \\
\text { of and respect } \\
\text { for diversity }\end{array}$ & & $\begin{array}{l}\text { Trauma policies and } \\
\text { services that respect } \\
\text { culture, race, ethnicity, } \\
\text { gender, age, sexual } \\
\text { orientation, disability, } \\
\text { and socio-economic } \\
\text { status }\end{array}$ & $\begin{array}{l}\text { Delivering services } \\
\text { in a nonjudgmental } \\
\text { and respectful } \\
\text { manner }\end{array}$ & $\begin{array}{l}\text { Cultural } \\
\text { competence }\end{array}$ & $\begin{array}{l}\text { Work towards } \\
\text { cultural competence, } \\
\text { understand } \\
\text { contextual factors }\end{array}$ \\
\hline \multirow{2}{*}{$\begin{array}{l}\text { 3. Choice \& } \\
\text { Empowerment }\end{array}$} & $\begin{array}{l}\text { b. } \\
\text { Empowermen } \\
\text { t model }\end{array}$ & $\begin{array}{l}\text { Empowerment: prioritize } \\
\text { consumer empowerment, } \\
\text { skill-building, and growth }\end{array}$ & & $\begin{array}{l}\text { Avoiding } \\
\text { provocation and } \\
\text { power assertion }\end{array}$ & $\begin{array}{l}\text { Open } \\
\text { communication: } \\
\text { provide } \\
\text { information } \\
\text { openly to } \\
\text { consumers }\end{array}$ & $\begin{array}{l}\text { Use an } \\
\text { empowerment } \\
\text { model }\end{array}$ \\
\hline & $\begin{array}{l}\text { c. Consumers } \\
\text { involved in } \\
\text { service } \\
\text { development } \\
\text { and } \\
\text { evaluation }\end{array}$ & $\begin{array}{l}\text { Collaboration: maximize } \\
\text { collaboration and sharing } \\
\text { of power between staff and } \\
\text { consumers }\end{array}$ & & $\begin{array}{l}\text { Sharing power in } \\
\text { the running of } \\
\text { shelter activities }\end{array}$ & $\begin{array}{l}\text { Shared power } \\
\text { and governance }\end{array}$ & $\begin{array}{l}\text { Involve consumers } \\
\text { in design and } \\
\text { evaluation of } \\
\text { services }\end{array}$ \\
\hline
\end{tabular}

assessments were generally designed as a first step, prior to initiating a more formal organizational self-assessment or to beginning programmatic shifts. Several findings emerged from a review of these needs assessments:

- $\quad$ Providers feel that they need to be better informed about trauma and violence $[17,18]$. Directors and staff within state domestic violence coalitions reported that many shelters are unprepared to deal with the complex needs of the women they serve, many of whom have few resources and have been victimized as children and as adults. Domestic violence advocates reported an increasing awareness of the need for services appropriate for women with mental health issues, substance abuse problems, and histories of abuse. They also expressed a need for guidance and resources in improving their responses to survivors of domestic violence who have experienced multiple abuses throughout their lives [18]. A multi-site program implementing trauma-informed services found that prior to implementation, sites had little knowledge about trauma, how to facilitate recovery, or how services might help or retraumatize survivors [19].

- Many providers do not have systematic ways of assessing for trauma-related issues. In a study examining PTSD screening and referral practices in VA addiction treatment programs, they found that although one-half to two-thirds of clinicians did routinely screen for trauma exposure and posttraumatic stress symptoms, assessments were generally not conducted systematically and did not utilize validated measures [20].

- Consumers want services that are empowering. Qualitative research has suggested that homeless individuals and families need and want trauma-informed services, including desire for autonomy, prevention of further victimization, and assistance in restoring their devalued sense of identity [21]. A provider guidebook, written from a consumer perspective, notes the need for accessible and effective programs for trauma survivors [22]. 
- Mental health services are an important need for many homeless families and individuals. In a multisite research study on trauma-informed services for homeless families, researchers examined current service needs, including families' need for social capital (educational or employment-related interventions), physical health, and mental health/substance use treatment. Among the families, they found that "mental health needs were the most prevalent of all the intervention needs components across sites (62\%), " with many facing multiple challenges, signaling the need for comprehensive intervention [23].

The results of these needs assessments supported the central importance of dealing with trauma within homelessness service settings and the perceived need for TIC.

Trauma-Informed Care within Homelessness Services Settings: Attitudes, Implementation, and Outcomes

Once the perceived need for trauma services is established, we can begin to explore the development of a TIC framework within homelessness service settings. We reviewed available quantitative, qualitative, and corroborative evidence regarding trauma-informed services.

Prochaska's stages of change model [24] highlights the fact that change is a process for individuals, who progress through precontemplation, contemplation, action, and maintenance of change. Similarly, systems change is a multi-step process. Our review of the literature highlighted three areas of evidence: attitudes, implementation, and outcomes. "Attitudes" refers to the beliefs of consumers and providers (at all levels, from management to front-line workers) of the need for a paradigm shift, confidence in ability to institute a paradigm shift, and belief that such a shift will lead to positive outcomes. "Implementation" coincides with Prochaska's action stage of change. It is a process variable, and is concerned with how changes are made. Implementation requires a clear definition of what is meant by Trauma-Informed Care, in order to translate these principles into concrete changes that will be instituted within the system. Finally, "outcomes" refers to the impact of a paradigm shift to TIC within homelessness service settings. Measurable objectives help to assess the efficacy of systems change. Outcomes may include measurable quantitative outcomes, such as a decrease in recidivism in homelessness, or qualitative outcomes, such as self-esteem or satisfaction with services.

\section{Review of the Evidence: What Do We Know About TIC?}

In our review of the evidence for TIC, several salient points emerged:

\section{Attitudes}

- Programs attempting to implement TIC have encountered some concerns and resistance on the part of providers. Providers may be afraid that addressing trauma will open a "Pandora's box" of reactions. They may lack confidence in their ability to manage and address trauma reactions and may be concerned that they will encounter triggers of their own trauma histories [19]. They may also worry that they will not have the resources to adequately respond to the complex needs of survivors.
- $\quad$ Because of these concerns, taking the time to build "buy-in" is particularly important. Recognizing the importance of commitment in organizations, some programs have developed committee structures geared towards obtaining "buy-in" from administration, program staff, and consumers. Building strong relationships also aided buy-in and integration of services [19]. After building agencywide commitment, programs have found strong support from staff members for implementing a trauma-informed model [25].

- Consumers want providers who are empathic and caring, who provide validation, and who offer emotional safety-characteristics of traumainformed providers. Consumers have emphasized the benefits of working with trauma-informed providers. Some have suggested that programs could benefit from having more trauma services, that practitioners need to remain patient, and that consumers themselves need to be invested in actively addressing their own issues [26]. However, even within trauma-informed systems, consumers sometimes struggle to feel empowered within a larger service system [27].

\section{Implementation}

- Training is central to implementing TIC. The majority of programs working to build TIC utilized staff training to increase awareness of and sensitivity to trauma-related issues. A large multi-site study of trauma-informed models found that "training on trauma for non-trauma providers was the first and most important step in making services more traumainformed" [19].

- Ongoing supervision, consultation, and support are needed to reinforce trauma-based concepts. One lesson from WCDVS was the importance of ongoing supervision and support to ensure that the environment is trauma-informed and that staff members practice appropriate self-care. Many programs also used external trauma consultants and ongoing training to reinforce knowledge and commitment to building trauma-informed services [19].

- Assessment and screening are important aspects of trauma-informed services. Research documenting high prevalence rates of trauma among people experiencing homelessness has led to the conclusion that screening for trauma is important within homeless service settings [28]. Although providers have at times expressed concern that inquiring about trauma histories will lead to traumatic stress responses, findings indicate that there are few adverse reactions to screening and assessment. Instead, most people benefit from this type of assessment [29]. Several pilot studies show that providers refined their intake processes to include screening for trauma exposure [28, 30]. Additionally, screening and assessment tools should be revised and refined with consumer and provider feedback [29]. 
- Because homeless individuals often have a multitude of service needs, comprehensive and integrated services are essential. Studies have found that service settings offering integrated counselingaddressing trauma, mental health, and substance use issues-had better results than settings that were not integrated [31].

- Integrating trauma-informed services for children is also important. Children of parents who are dealing with trauma, mental illness, substance abuse, and/or homelessness may be at greater risk for adverse outcomes. A number of programs working to integrate trauma-informed services have also highlighted the importance of parallel services for children. In WCDVS, a subset of sites offered specialized children's programs, including assessment, groups, and resource coordination/advocacy for children to build coping skills, strengthen interpersonal relationships, and develop positive identity and self-esteem [32].

- Many factors challenge implementation of trauma-informed services. Various reports highlighted the logistical difficulties of systems change. Change, especially within larger systems, can be time-consuming and requires a great deal of commitment across all levels of an organization. Organizational resistance and stress can be a barrier to larger systems change [33]. Moses highlighted challenges to systems change across a number of sites working to implement integrated, trauma-informed services for women with co-occurring disorders. These challenges included philosophical differences between mental health and substance use treatment approaches, differences around issues of trauma, resistance at the service and administrative levels, limited resources, difficulties in achieving consistent participation in trauma groups, staff turnover, and the difficulty of change in general [13].

- Implementing a trauma-informed model can lead to changes in how an organization functions. In a program implementing a trauma-informed model, staff reported a number of changes within their programs, including increased awareness and sensitivity about trauma, intake that incorporates questions about trauma, more freedom and choice given to consumers regarding their treatment, and environmental changes that led to increases in safety, confidentiality, and a more welcoming atmosphere [30].

- Including consumers in developing and evaluating trauma-informed services is important. Although there has not yet been research that examines differences in services that include or do not include consumers in program development and evaluation, current wisdom in the field stresses the importance of including consumers in all aspects of programming $[34,35]$. This wisdom is consistent with theories on empowerment, which suggest that survivors should be given agency in effecting their own outcomes [36]. The WCDVS found that integrating consumers into the design and evaluation of services had a profound impact on the systems involved [19], and that "integral to the... group's personal and professional growth was the development and expression of their individual and collective voices" [27].

- Cultural competence is important in developing TIC. Because trauma may have different meanings in different cultures, and because traumatic stress may be expressed differently within different cultural frameworks, it is important for providers within a trauma-informed system to work towards developing cultural and linguistic competence [13].

\section{$\underline{\text { 3. Outcomes }}$}

- Trauma-informed service settings, with traumaspecific services available, have better outcomes than "treatment as usual" for many symptoms. We know from a variety of studies [31, 37] and pilot programs [38] that setting that utilize a traumainformed model report a decrease in psychiatric symptoms and substance use. Some of these programs have shown an improvement in consumers' daily functioning and a decrease in trauma symptoms, substance use, and mental health symptoms. These findings suggest that integrating services for traumatic stress, substance use, and mental health leads to better outcomes [16].

- $\quad$ TIC for children lead to better outcomes, such as better self-esteem, improved relationships, and increased safety. A subset of programs within WCDVS examined the impact of a standardized, trauma-informed intervention for children, consisting of a clinical assessment, coordination of resources and advocacy, and a psycho-educational skillsbuilding group. One year later, children in the intervention group had more positive self-identity, increased tools for building healthy relationships, and improved safety. These changes were particularly striking for children who had witnessed violence [32, 39].

- Early indications suggest that TIC may have a positive effect on housing stability. A multi-site study of TIC for homeless families found that, at 18 months, $88 \%$ of participants had either remained in Section 8 housing or moved to permanent housing [23]. An outreach and care coordination program that provided family-focused, integrated, trauma-informed care to homeless mothers in Massachusetts found that the program led to increased residential stability [38].

- TIC may lead to a decrease in crisis-based services. Some studies have found decreases in the use of intensive services such as hospitalization and crisis intervention following the implementation of trauma-informed care [40].

- Trauma-informed, integrated services are costeffective. Because trauma-informed integrated services have improved outcomes but do not cost more than standard programming, they are judged to be cost-effective [41].

- Qualitative results find that providers report positive outcomes in their organizations from 
implementing TIC. Providers report greater collaboration with consumers, enhanced skills, and a greater sense of self-efficacy among consumers, and more support from their agencies. Supervisors report more collaboration within and outside their agencies, improved staff morale, fewer negative events, and more effective services [40].

- Qualitative results indicate that consumers respond well to TIC. Within the D.C. Trauma Collaboration study, consumers reported an increased sense of safety, better collaboration with staff, and a more significant "voice." Eighty-four \% of consumers rated their overall experience with these traumainformed services using the highest rating available [42]. Survey results suggest that consumers were very satisfied with trauma-informed changes in service delivery [25].

These results reinforce the need for TIC, assist in further defining TIC, clarify the process of implementation, and suggest the efficacy of TIC for certain outcomes. However, in our review, we found that various questions were not addressed by available evidence. These gaps in the available evidence are important in highlighting the additional work that remains to be done to implement TIC in homelessness service settings.

\section{Review of the Evidence: What Do We Not Know About TIC?}

Our review of the literature highlighted several directions for future exploration:

\section{Attitudes}

- $\quad$ Although providers and consumers alike generally pay lip service to the idea of TIC, we do not know the extent to which their attitude is influenced by demand. In much of the research to date, providers and consumers were given brief questionnaires or were interviewed - in many cases, by the individuals working to build trauma-informed services. Thus, there may be a tendency to indicate support of implementation plans and strategies in the absence of true commitment.

\section{Implementation}

- We do not know exactly what constitutes "traumainformed care." Trauma has become a buzz-word recently, with many agencies and workgroups noting the importance of becoming "trauma-informed." However, definitions of "trauma-informed" and how these ideas are implemented vary widely. There is generally a lack of specificity in how agencies are defining "trauma-informed," and how this relates to actual practice.

- We do not have a clear method for measuring the degree to which a program is trauma-informed. Because of the lack of definitions and behaviorallydefined changes signifying trauma-informed services, there is no consistent basis for identifying whether or not and to what degrees a program is traumainformed.
- We do not know how special populations respond to trauma-informed homelessness services. Much of the evidence on trauma-informed homelessness systems concerns women and children. We know less about the response of other groups, such as men, veterans, individuals from ethnic/racial minorities or other cultures, and lesbian, gay, bisexual and transgendered (LGBT) individuals.

\section{Outcomes}

- We do not know whether differences in outcomes are based on trauma-informed environments, trauma-specific interventions, or both. Because many service settings that provide TIC also offer trauma-specific services, the extent to which each component contributes to change is difficult for research studies to determine.

- We do not know whether trauma-informed services are effective specifically within homeless services. Although the research in other fields suggests that trauma-informed services may be effective for homeless individuals, there have yet to be any rigorous, quantitative studies exploring outcomes within homelessness service settings. The results of the Homeless Families Program, a current multi-site evaluation of trauma-informed homelessness services, may begin to shed some light on this issue.

Our review of the current evidence suggests that TIC is an important area for further exploration. Initial feedback appears to support the assertion that TIC has a positive impact on both the process and outcome of service provision within homelessness service settings. However, the review highlighted as many questions and gaps as it defined results and conclusions.

Because the implementation of TIC within homelessness service settings is in its infancy, it is particularly important to review lessons from the field, including self-assessments and frameworks that are being developed to guide the paradigm shift to TIC, as well as feed back from local, regional, and national programs and initiatives that are implementing TIC. Lessons from the field highlight clinical insights, new practice initiatives, and areas in need of further qualitative and quantitative research.

\section{Corroborative Evidence: Lessons from the Field on Building TIC in Homelessness Service Systems}

When we look to the field for best practices and clinical wisdom, we find a wealth of information about current theories, practices, programming, and policy initiatives. This information tells us that although we do not yet have substantial outcome-based research supporting the effectiveness of TIC, there is considerable activity in the field that is awaiting additional documentation. Many homeless service systems are beginning to address this issue-administrators, providers, consultants, and consumers are working together to transform programs into environments that offer TIC.

After recognizing the pervasiveness of traumatic stress among people experiencing homelessness, various programs are taking steps to become more trauma-informed. We have 
selected several case examples to describe the ways in which homeless service settings are striving to become more trauma-informed. This is not a comprehensive list of traumainformed resources and programs. Instead, it is intended to illustrate various creative ways that programs are implementing trauma-informed models within homeless service systems, and some of the tools that are available to aid this transition.

\section{Selected Promising Models}

To foster the development of trauma-informed homeless service settings without reinventing the wheel within each individual program, innovators have developed frameworks and models that can serve as guides for implementing TIC. Various models have been proposed that support organizational change towards a model of TIC and that guide trauma-informed service delivery. Some of these models are:

- Attachment, Regulation, and Competency: A Comprehensive Framework for Intervention with Complexly Traumatized Youth (ARC) [43]

- $\quad$ Child Adult Relationship Enhancement (CARE)

- $\quad$ A Long Journey Home [44]

- $\quad$ Phoenix Rising [45]

- $\quad$ Sanctuary Model [46]

- Using Trauma Theory to Design Service Systems [12]

Table 2 describes each of these models, the applications of the models, and available evidence supporting their effectiveness. These models of TIC emphasize staff education, involving consumers, and transforming systems to be responsive to the needs of trauma survivors. Several models, including ARC, CARE, and Sanctuary, have an evidence base (e.g., outcomes-based quantitative research) in the mental health field (including inpatient and outpatient settings) and are considered to be promising practices in trauma-informed care [46]. Others, such as A Long Journey Home and Phoenix Rising, were developed specifically for homeless service settings. Most of these models have been implemented within homeless service settings, and process and outcome evaluation data are currently being collected.

\section{HOW TRAUMA-INFORMED ARE WE? ORGANIZATIONAL SELF-ASSESSMENTS}

The models described above highlight the need for a framework that provides the foundation for a paradigm shift within homelessness service systems. Once a model for TIC has been identified, an organizational self-assessment can be utilized as a starting point for systems change.

Self-assessment targets specific areas for change and indicates how a service delivery model might be adapted to an organization's unique needs. As the model is implemented, a self-assessment is a useful reminder about important aspects of trauma-informed care that facilitate selfmonitoring and program evaluation. Organizational selfassessments can also be conducted after implementation of a paradigm shift in order to evaluate the effectiveness of the systems change.
Several trauma-informed organizational self-assessments are currently available or/are in development. They include:

- The Collaboration on Trauma-Surviving Homeless Children, a partnership between the National Center on Family Homelessness and the Trauma Center at Justice Resource Institute (JRI), has developed the Trauma-Informed Organizational Self-Assessment for Programs Serving Homeless Families [50] to help programs assess the degree to which their services are trauma-informed and to highlight areas for change. The self-assessment addresses organizational issues such as delineating program mission, guidelines, and policies; reviewing services and policies; establishing a safe and trauma-informed physical environment; respecting consumer needs and differences; protecting consumer privacy and information; encouraging internal and external community-building; and involving consumers in program development and evaluation. The instrument evaluates staff issues, including hiring practices, staff training and education, and supervision and support. It also assesses consumer issues, including procedures for arrival and intake; safety-planning and crisis prevention; goal setting; and availability of services, including trauma-specific interventions.

- The Trauma Center at JRI has developed the Trauma-Informed Facility Assessment [49], a brief instrument assessing the degree to which an organization's physical space is trauma-informed. This assessment defines several characteristics that are of primary importance for trauma-informed organizations, including physical safety, absence of triggering material, privacy/ confidentiality, and structure and predictable/consistent response. Other areas measured by the instrument include accessibility; organization and hygiene; the ability to meet the basic needs of consumers and provide links to resources; the availability of personal/quiet space; the communication of positive messages; and the creation of a sense of community, with consumer ownership of the space and the program.

- Community Connections has developed a TraumaInformed Program Self-Assessment Scale and Planning Protocol [51]. This tool allows organizations to evaluate the degree to which program activities and settings are consistent with five guiding principles: safety, trustworthiness, choice, collaboration, and empowerment. Six major domains are evaluated, including: program procedures and settings; formal services policies; trauma screening, assessment, and service planning; administrative support for program-wide traumainformed services; staff trauma training and education; and human-resource practices. Each domain is evaluated on the basis of review of program policies, standard program activities, review of physical space, staff ratings, and consumer ratings.

- As part of a larger study examining integrated trauma-informed treatment for women with 
Table 2. Models of Trauma-Informed Care

\begin{tabular}{|c|c|c|c|c|c|c|c|}
\hline Model & Developers & Description & Key Principles & Applications & $\begin{array}{l}\text { Research } \\
\text { Evidence }\end{array}$ & Strengths & Limitations \\
\hline $\begin{array}{l}\text { The ARC } \\
\text { Model } \\
\text { (Attachment, } \\
\text { Self-Regulation, } \\
\text { and } \\
\text { Competency): A } \\
\text { Comprehensive } \\
\text { Framework for } \\
\text { Intervention } \\
\text { with Complexly } \\
\text { Traumatized } \\
\text { Youth }\end{array}$ & $\begin{array}{l}\text { Kinniburgh } \\
\text { and } \\
\text { Blaustein [48] }\end{array}$ & $\begin{array}{l}\text { - ARC is a } \\
\text { flexible } \\
\text { framework for } \\
\text { intervention } \\
\text { with } \\
\text { children/famil } \\
\text { ies who have } \\
\text { experienced } \\
\text { complex } \\
\text { trauma. ARC } \\
\text { has been } \\
\text { adapted for } \\
\text { use within } \\
\text { various } \\
\text { milieus. } \\
\text { - It has been } \\
\text { applied within } \\
\text { homeless } \\
\text { settings for } \\
\text { runaway and } \\
\text { homeless } \\
\text { youth. }\end{array}$ & $\begin{array}{l}\text { - } 10 \text { building blocks, } \\
\text { based on three basic } \\
\text { principles: } \\
\text { Attachment, } \\
\text { Regulation, and } \\
\text { Competency. } \\
\text { - Attachment: } \\
\text { Caregiver affect } \\
\text { management, } \\
\text { attunement, consistent } \\
\text { responses, routines } \\
\text { and rituals. } \\
\text { - Regulation: Affect } \\
\text { identification, } \\
\text { modulation, and } \\
\text { expression. } \\
\text { - Competency: } \\
\text { Executive functions, } \\
\text { self-development \& } \\
\text { identity, \& } \\
\text { developmental tasks. }\end{array}$ & $\begin{array}{l}\text { Therapeutic } \\
\text { Procedures: } \\
\text { - Psycho- } \\
\text { education; } \\
\text { - Relationship } \\
\text { strengthening; } \\
\text { - Social skills; } \\
\text { - Parent-education } \\
\text { training. } \\
\text { - ARC principles } \\
\text { adapted for use } \\
\text { with homeless } \\
\text { adolescents. } \\
\text { - ARC Agency } \\
\text { Inventory for } \\
\text { homeless/ } \\
\text { runaway youth } \\
\text { has been } \\
\text { developed. }\end{array}$ & $\begin{array}{l}\text { - Pilot data: } \\
\text { ARC is } \\
\text { effective in } \\
\text { outpatient } \\
\text { settings. } \\
\text { - Quasi- } \\
\text { experimental } \\
\text { research } \\
\text { studies: } \\
\text { conducted in } \\
\text { outpatient and } \\
\text { milieu settings } \\
\text { in MI, IL, CA, } \\
\text { AL, \& MA. } \\
\text { Outcomes: } \\
\text { decreased } \\
\text { trauma } \\
\text { symptoms, } \\
\text { PTSD, and } \\
\text { internalizing/ } \\
\text { externalizing } \\
\text { symptoms. } \\
\text { - ARC } \\
\text { concepts- } \\
\text { adapted for } \\
\text { use in } \\
\text { homeless } \\
\text { settings but } \\
\text { not yet been } \\
\text { evaluated. }\end{array}$ & $\begin{array}{l}\text { Very strong } \\
\text { theoretical basis. } \\
\text { Addresses } \\
\text { developmental } \\
\text { trauma. } \\
\text { Offers a } \\
\text { comprehensive } \\
\text { framework for } \\
\text { milieu change; } \\
\text { provides a model } \\
\text { for trauma- } \\
\text { specific } \\
\text { interventions. } \\
\text { Well-defined, } \\
\text { with an extensive } \\
\text { manual and } \\
\text { comprehensive } \\
\text { training } \\
\text { NCTSN calls it a } \\
\text { "promising } \\
\text { practice" } \\
\text { Collecting } \\
\text { evidence on } \\
\text { effectiveness at } \\
\text { multiple sites. }\end{array}$ & $\begin{array}{l}\text { - Although } \\
\text { evaluated in } \\
\text { multiple } \\
\text { outpatient } \\
\text { and milieu } \\
\text { settings, it } \\
\text { has yet to } \\
\text { be formally } \\
\text { evaluated in } \\
\text { homeless } \\
\text { settings. }\end{array}$ \\
\hline $\begin{array}{l}\text { CARE } \\
\text { (Child Adult } \\
\text { Relationship } \\
\text { Enhancement) }\end{array}$ & \begin{tabular}{|l|} 
Trauma \\
Treatment \\
Training \\
Center \\
(TTTC). \\
Revised for \\
homeless \\
populations by \\
NCFH \& the \\
Trauma \\
Center.
\end{tabular} & $\begin{array}{l}\text { - Trauma- } \\
\text { informed } \\
\text { modification } \\
\text { of Parent } \\
\text { Child } \\
\text { Interaction } \\
\text { Therapy } \\
\text { (PCIT). } \\
\text { - Skill-based } \\
\text { model for use } \\
\text { in milieu } \\
\text { settings. } \\
\text { - Being } \\
\text { modified for } \\
\text { homeless } \\
\text { settings. }\end{array}$ & $\begin{array}{l}\text { CARE guides caregivers } \\
\text { in child-directed and } \\
\text { parent-directed } \\
\text { interactions: } \\
\text { - Caretakers' } \\
\text { competence in } \\
\text { managing child's } \\
\text { problematic } \\
\text { behaviors; } \\
\text { - Caretakers' } \\
\text { competence } \\
\text { reinforcing + } \\
\text { behaviors; } \\
\text { - Reduce parent-child } \\
\text { conflict; and } \\
\text { - Enhance positive } \\
\text { parent-child } \\
\text { interactions. }\end{array}$ & $\begin{array}{l}\text { - Trauma } \\
\text { education } \\
\text { component. } \\
\text { - Live coaching. } \\
\text { - Practice of } 3 \mathrm{P} \\
\text { Skills (Praise, } \\
\text { Paraphrase, and } \\
\text { Point-Out } \\
\text { Behavior) to } \\
\text { guide parent- } \\
\text { child } \\
\text { interactions. }\end{array}$ & $\begin{array}{l}\text { - CARE is } \\
\text { empirically } \\
\text { informed but } \\
\text { has not yet } \\
\text { been } \\
\text { evaluated. } \\
\text { - PCIT, the } \\
\text { foundation } \\
\text { for CARE, } \\
\text { has been } \\
\text { empirically } \\
\text { supported by } \\
\text { numerous } \\
\text { studies. } \\
\text { - Piloted in } \\
\text { shelters }\end{array}$ & $\begin{array}{l}\text { - Modified PCIT- } \\
\text { Strong } \\
\text { theoretical \& } \\
\text { research base } \\
\text { - Effective for } \\
\text { building }+ \\
\text { caregiver/child } \\
\text { relationships \& } \\
\text { building } \\
\text { caregiver } \\
\text { competence. } \\
\text { - NCTSN calls it } \\
\text { a promising } \\
\text { practice }\end{array}$ & $\begin{array}{l}\text { - Limited } \\
\text { scope in } \\
\text { terms of } \\
\text { systems } \\
\text { change. } \\
\text { - Does not } \\
\text { yet have an } \\
\text { evidence } \\
\text { base within } \\
\text { homelessne } \\
\text { ss. }\end{array}$ \\
\hline $\begin{array}{l}\text { A Long } \\
\text { Journey Home }\end{array}$ & $\begin{array}{l}\text { Prescott, L. } \\
\text { and NCFH } \\
\text { [44] }\end{array}$ & $\begin{array}{l}\text { A Guide for } \\
\text { Creating } \\
\text { Trauma- } \\
\text { Informed } \\
\text { Services for } \\
\text { Homeless } \\
\text { Mothers and } \\
\text { Children }\end{array}$ & $\begin{array}{l}\text { Offers guidance on: } \\
\text { - } \text { Changing the } \\
\text { environment } \\
\text { - Trauma-informed } \\
\text { policies and } \\
\text { procedures } \\
\text { - Trauma-informed } \\
\text { services \& support } \\
\text { - Client representation } \\
\text { \& staff development } \\
\text { - Training and } \\
\text { supervision } \\
\text { - Developing } \\
\text { sustainability }\end{array}$ & $\begin{array}{l}\text { - Guide offers } \\
\text { concrete } \\
\text { suggestions for } \\
\text { organizational } \\
\text { shift towards } \\
\text { TIC } \\
\text {-Includes concrete } \\
\text { examples, } \\
\text { exercises, \& } \\
\text { suggestions for } \\
\text { staff training. }\end{array}$ & $\begin{array}{l}\text { - In the final } \\
\text { stages of } \\
\text { developme } \\
\text { nt; has not } \\
\text { been } \\
\text { piloted in } \\
\text { homeless } \\
\text { service } \\
\text { settings. }\end{array}$ & $\begin{array}{l}\text { - Practical guide } \\
\text { for making } \\
\text { concrete changes } \\
\text { within systems. } \\
\text { - Developed } \\
\text { specifically for } \\
\text { trauma-informed } \\
\text { systems change } \\
\text { within homeless } \\
\text { service settings. }\end{array}$ & $\begin{array}{l}\text { - Still in } \\
\text { developme } \\
\text { nt --does } \\
\text { not yet } \\
\text { have a } \\
\text { research or } \\
\text { practice } \\
\text { evidence } \\
\text { base. }\end{array}$ \\
\hline
\end{tabular}




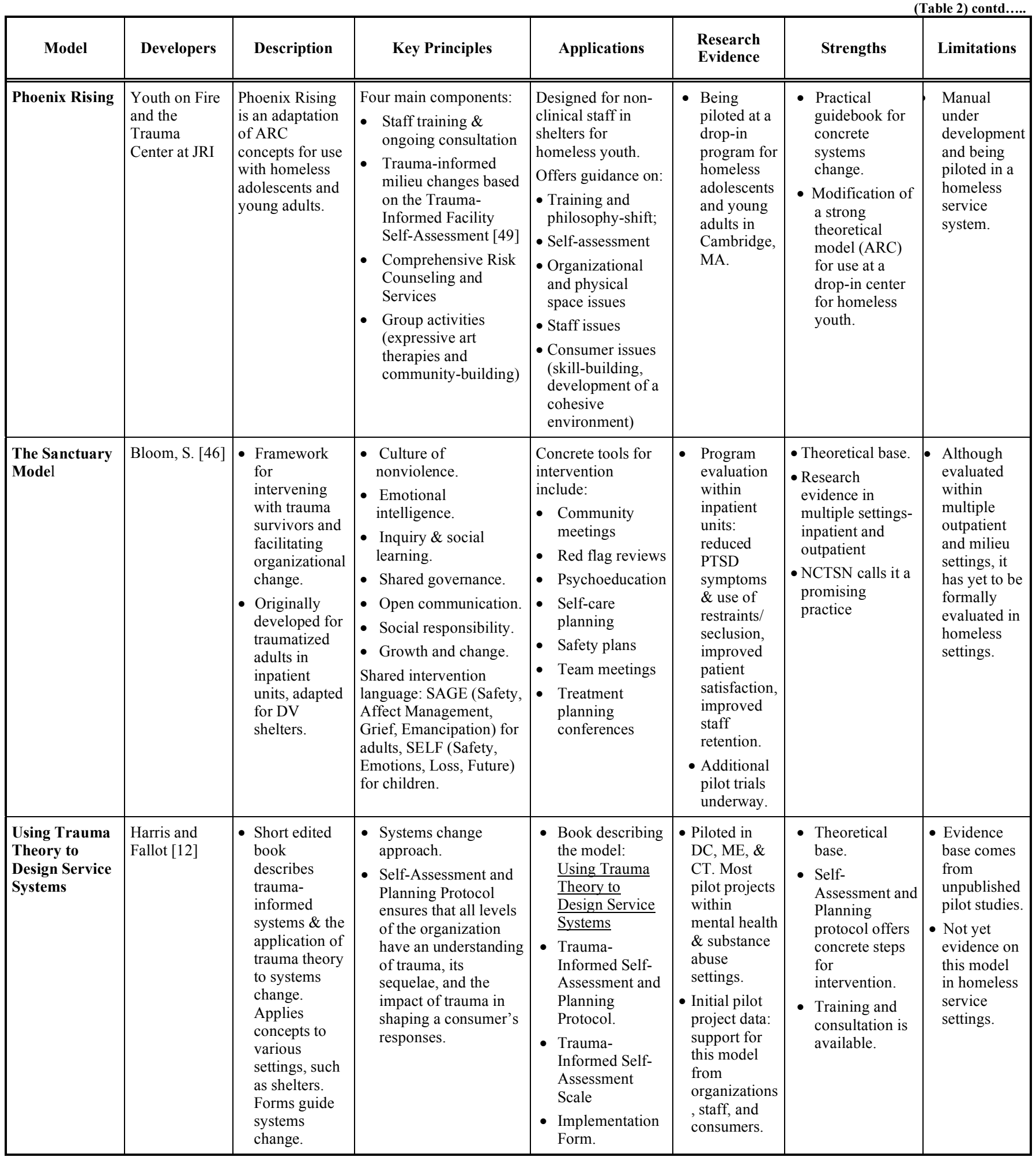

co-occurring disorders, the W.E.L.L. Project of the Institute for Health and Recovery (IHR) developed a toolkit for developing trauma-informed organizations. This self-assessment tool, entitled Developing Trauma-informed Organizations: A Toolkit [52], includes principles of trauma-informed treatment, a self-assessment for provider organizations, and an organizational assessment for non-provider organizations.
Although these self-assessment tools-like the service delivery models - are still in development and refinement stages, they reflect advances towards the development of TIC.

\section{INNOVATIVE PROGRAMS AND INITIATIVES UTILIZING TIC}

The development of these models and self-assessment tools has facilitated the progress of a number of innovative 
programs that are working to build TIC within homelessness service systems. We selected various programs that illustrate lessons from the field with diverse populations experiencing homelessness.

\section{Trauma-Informed Family Shelters}

- $\quad$ The Collaboration on Trauma-Surviving Homeless Children - a partnership among the National Center on Family Homelessness, the Trauma Center at Justice Resource Institute, and other agencies - has worked with various shelters within the Boston metropolitan area to build trauma-informed homeless services. Experts in trauma and homelessness worked jointly to develop trauma-based training and consultation targeted specifically to the needs of homeless families. Trauma training was offered to all levels of program staff, from administrators to clinical case managers to family advocates. Staff participated in regular trauma team meetings that focused on both trauma-informed organizational change and traumafocused case consultation. Trauma-informed programming was also instituted within shelter settings. This included community-building activities, an expressive music program, and self-care activities for residents. The goal of this program was to increase the staff's knowledge of traumatic stress, their skill level in responding to trauma-related issues, their self-efficacy about working with individuals and families who have been traumatized, and their awareness of issues related to vicarious trauma and burnout, and self-care. Initial evaluation results indicated positive outcomes, with high levels of support for the organizational shift to traumainformed programming, increased staff confidence, fewer resident conflicts, better relationships among staff and residents, and fewer resident terminations.

\section{Trauma-Informed Domestic Violence Shelters}

- $\quad$ The Domestic Violence (DV) and Mental Health Policy Initiative in Chicago is working with the Department of Public Health, the Mayors Office, and several domestic violence shelters to create three "Centers of Excellence" for trauma and domestic violence. This pilot program will evaluate changes among organizations, providers, and survivors. The initiative is also developing a DV-Trauma Core Curriculum to assist providers in offering more trauma-informed services within domestic violence programs.

\section{Trauma-Informed Homeless Outreach Programs}

- The Women's Violence Prevention Project Alliance at the Friends of the Shattuck shelter in Boston is an outreach program for homeless men and women that is working towards becoming more trauma-informed. This program developed a manual to help providers and outreach workers build their understanding of trauma and learn how to respond appropriately to survivors. The manual also includes a safety-planning guide for use with individuals who are living on the streets.

\section{Trauma-Informed Programs for Homeless Youth}

- Youth on Fire is a drop-in center for homeless adolescents and young adults in Cambridge, Massachusetts. This program utilizes the Phoenix Rising model, an adaptation of ARC (Attachment, Self-regulation, and Competency model) for homeless and at-risk youth. Program staff members have received trauma training and continue to receive trauma consultation from the Trauma Center at Justice Resource Institute. They are working to modify their environment to become more traumainformed. This program also offers trauma-specific group interventions.

- The Community Trauma Treatment for Runaway and Homeless Youth is a partnership among several agencies in the Los Angeles area that provides outreach and services to homeless youth. This program has utilized the ARC model to institute a philosophical shift towards becoming traumainformed. They developed an ARC-based organizational self-assessment in order to target areas for change within participating agencies. They have also instituted trauma-informed case conference meetings in which ARC concepts are used for case review. Trauma-specific interventions have also been instituted within this program.

- $\quad$ The Homeless Children's Network is a consortium of fifteen homeless and domestic violence programs in San Francisco, California. This program provides therapy and case management to homeless children and their families. Their theoretical framework considers homelessness to be a traumatic stressor for children.

Trauma-Informed Treatment Programs for Homeless People with Co-Occurring Mental Health and Substance Use Problems

- The Seeking Treatment and Recovery (STAR) Program in Florida provides treatment for homeless people who are suffering from co-occurring mental illness and substance abuse. After determining that $79.5 \%$ of the homeless individuals served by their program acknowledged a history of physical or sexual abuse, this program began to make changes to become more trauma-informed. The program instituted a formal process of screening for trauma exposure. Based on the high level of trauma exposure reported by men, they expanded the trauma-specific services to include treatment for male survivors. The program also incorporated various training activities to raise trauma awareness and to build traumainformed services [28].

\section{Programs Utilizing a Trauma Framework for Veterans}

- Mary E. Walker House is a transitional-living program for homeless women veterans in Coatesville, Pennsylvania, that focuses on recovery from trauma and substance abuse. This program includes a trauma framework and also offers trauma-specific services. 
- The Renew program is a V.A. program in Long Beach, California, which serves both homeless and non-homeless women veterans who have experienced military sexual trauma, and often pre-military sexual trauma.

- New Directions is a V.A. program in Los Angeles, California, that offers substance abuse and mental health treatment utilizing a trauma framework. Its Women's Program offers trauma counseling, with $100 \%$ of clients reporting abuse. The Executive Director noted, "Most of our clients have experienced multiple traumas, including physical trauma as a child, military trauma and years of abuse on the streets and in prisons. Since veterans are known to have a higher degree of trauma than the general public, it would be most cost effective to begin to treat trauma as the core disability rather than separate and apart from all other symptoms" [53].

These program examples illustrate the beginning of a paradigm shift in which homeless services sites are recognizing the central role of trauma in the lives of consumers. These programs are being implemented in diverse settings including family-based shelters, domestic violence programs, outreach programs, dual diagnosis programs for homeless individuals, and programs for homeless youth and veterans. However, this shift is only beginning. Many programs do not yet recognize the central role of trauma. Guidance from state and federal initiatives is likely to facilitate broader awareness of the need for TIC within behavioral health systems and, more specifically, within homelessness services settings.

\section{SELECTED STATE AND FEDERAL INITIATIVES TO ESTABLISH TIC}

Over the past ten years, various state and federal policies have focused on the importance of establishing traumainformed services within mental health and substance abuse settings. In 1998, the National Association of State Mental Health Program Directors (NASMHPD) issued a position statement on services and supports for trauma survivors, recognizing that "the psychological effects of violence and trauma in our society are pervasive, highly disabling, yet largely ignored." The statement articulated a commitment to address the issue of trauma. The report, Models for Developing Trauma-Informed Behavioral Health Systems and Trauma-Specific Services, defined "trauma-informed" and described programs that have implemented traumainformed models on a statewide or local level [54]. NASMHPD also developed a Trauma Services Implementation Toolkit for State Mental Health Agencies [42] that describes products being used by various state agencies to work towards building trauma-informed systems. Although these policy documents are not directed towards homeless service systems, they provided momentum in the social-services fields towards incorporating knowledge of trauma into service systems.

Regional and national initiatives regarding the need for TIC within the homelessness field are even more recent. Within the past ten years, a number of homeless service organizations and coalitions have begun to emphasize the importance of addressing the impact of trauma among individuals experiencing homelessness, and several training and technical assistance centers have emerged that are actively promoting trauma-informed homelessness services.

The Homelessness Resource Center (HRC), a SAMHSA-funded program, provides resources, training, and technical assistance on issues affecting people who are homeless. Its mission is to improve the lives of people who are homeless and have been impacted by trauma, substance abuse, and mental health issues. One of HRC's guiding principles is to foster trauma-informed recovery systems. Through its website, the HRC disseminates tips, tools, and knowledge-based products that can be used by programs interested in implementing trauma-informed care. See www.homeless.samhsa.gov.

The National Center for Trauma-Informed Care, funded by SAMHSA's Center for Mental Health Services (CMHS), offers educational materials, technical assistance, and training to social services systems to build an understanding of the impact of trauma and effective traumabased interventions. In collaboration with the Homelessness Resource Center, the National Center for Trauma-Informed Care offers trauma-informed training to providers in the Gulf Coast recovery area. In addition, training in trauma-informed care has been offered to Projects for Assistance in Transition from Homelessness (PATH) programs.

The National Child Traumatic Stress Network (NCTSN), another SAMHSA-supported program, has focused on the impact of traumatic stress in the lives of children. The Network has been active in promoting traumainformed care, including trauma awareness within homeless service settings for youth. The Homelessness and Extreme Poverty Working Group is a branch of NCTSN that devotes itself to the intersection of trauma, poverty, and homelessness in children.

The Department of Veterans Affairs offers specialized services to homeless veterans, and is increasingly addressing sexual trauma among female veterans. However, the National Coalition for Homeless Veterans noted that "with greater numbers of women in combat operations, along with increased identification of and a greater emphasis on care for victims of sexual assault and trauma, new and more comprehensive services are needed." The Coalition's 2007 public policy priorities include increasing homeless veterans' access to comprehensive, high-quality and affordable health care, including substance abuse and mental health care. Limitations still exist in the VA's policy on trauma-informed care for homeless veterans, particularly around the treatment of trauma (not necessarily combat-related) among male veterans.

The work of these initiatives has been integral to raising awareness of the need for trauma-informed homeless service systems. However, a large gap still remains between the recognition of trauma and the implementation of programs and policies that ensure available and accessible traumainformed care for homeless individuals and families. Further advances in practice, programming, policy, and research are needed to develop evidence-based, trauma-informed care within homeless services across the country. 


\section{DISCUSSION}

Our review of the current evidence suggested that, while there are challenges to implementing trauma-informed services, Trauma-Informed Care appears to be effective. We can conclude from research in other fields that, with necessary buy-in, TIC is well-received by consumers and providers, most likely leads to better outcomes, and does not cost significantly more than treatment as usual. Despite these promising findings, this review also highlighted what we do not yet know about TIC within homelessness services settings. There is a dearth of research on trauma-informed approaches specifically within homeless service settings. Most organizations that are working towards building trauma-informed homelessness service settings are collecting minimal or no information for evaluation purposes. The Homeless Families Program, a large quasi-experimental study examining trauma-informed services within homeless services, is an exception.

Initiated by the Substance Abuse and Mental Health Services Administration (SAMSHA) in 1999, the Homeless Families Program is the first large research study to examine integrated, trauma-informed care for homeless families with psychiatric disorders, substance use problems, and trauma histories. Each of the eight sites focuses on helping consumers understand the connection between their own trauma histories and their current issues; this education lays the groundwork for assisting consumers in developing new coping strategies and working to improve their parenting skills and relationships. The program also focuses on staff issues, including team-building, staff support, and self-care.

Although evaluation of the Homeless Families Program is still in progress, and final results are not yet available, preliminary findings have identified several factors that seem to be important for implementing trauma-informed services: 1) the trauma intervention approach should fit into the overall model and philosophy of the program; 2) programs should utilize strengths-based approaches in working with trauma survivors; 3) programs should encourage mutual respect and trustworthy behavior (e.g., following through on commitments); 4) programs should avoid punitive approaches, limiting rules and regulations to those ensuring safety; 5) staff should be encouraged to have realistic expectations about the progress that can be expected; 6) programs should engage survivors in the process of helping others (e.g., normalizing, empathizing, assisting, allowing transformative experiences); and 7) programs should maintain a nonjudgmental approach, while encouraging personal responsibility and the possibility of making better choices [55].

Clearly, although initial investigations are promising, the research to date is inadequate for evaluating the effectiveness of trauma-informed models within homeless service settings. Additional quantitative and qualitative research is needed to further explore trauma-informed practices specifically within homeless service settings. This research can be used to establish empirically-based best practices and will be the springboard for policy that can drive systems change in programs nationwide. Because the field is only beginning to generate research-based evidence on trauma-informed homelessness services, we have looked to the field for best practices and clinical wisdom in developing and implementing trauma-informed theories and practices.

\section{RECOMMENDATIONS}

This review documents the high rates of traumatic stress among people who experience homelessness and supports the need for developing trauma-informed services. While considerable progress has been made in increasing awareness of the impact of traumatic stress, the implementation of a widespread system of trauma-informed homeless services is in its early stages. Although this review highlights various innovative practices and programs that have been created in a wide array of settings for various subgroups of homeless people, they are relatively limited given the enormous need. Many program strategies and models are still being developed and piloted. Preliminary feedback from the homelessness arena and other service settings suggests that these approaches may be effective in producing better outcomes and promoting systems change. However, the evidence base supporting the effectiveness of these practices and programs is largely drawn from the corroborative literature.

The research base supporting the effectiveness of traumainformed services within homeless settings is limited. Over the past decade, trauma-informed services have begun to be implemented in other fields, including mental health and substance use programs. With this implementation has come some robust quantitative and qualitative research. Quantitative research from these fields indicates that traumainformed services are associated with improved outcomes, such as decreased mental health, trauma-related, and substance abuse symptoms and behaviors. Qualitative research from these fields has better described the meaning of trauma-informed care and has found that its implementation can be a challenging process, but that it can lead to systems changes that have positive impacts on both providers and consumers. Findings from these studies can inform best practices within the homelessness field.

Even with significant limitations in the research literature, we have learned important lessons about how we can best move ahead to make the homelessness service system more trauma-informed.

\section{Practice}

Despite the prevalence of trauma among individuals experiencing homelessness, many homeless service systems are not yet adequately addressing this issue. Greater uniformity and consistency of trauma-informed services for homeless individuals will aid in our understanding of the effectiveness of those practices.

Practice recommendations for building trauma-informed homeless services include the following:

1. Although a number of homeless services settings may be beginning to implement trauma-informed services, there is great variability in how these services are implemented. Utilization of a theory-based model or framework would help to ensure consistency across sites and help to begin to build evidence-based practices. 
2. Programs should strive to avoid any practices that may be retraumatizing. This applies to all levels of the system, including administrative, provider, and consumer levels.

3. Homeless service systems should implement universal systematic screening for trauma histories, using standardized measures.

4. Program intake and evaluation should include an assessment of consumer strengths and resources. This contributes to the development of a strengths-based model and supports the further development of coping resources.

5. Because research has found that integration of services is a key factor in improving outcomes, it is recommended that substance abuse, mental health, and trauma services be integrated.

6. Programs implementing integrated trauma-informed treatment approaches should also include traumainformed services for children, in order to increase resiliency in children and youth.

7. Because the majority of consumers in homeless service settings are trauma survivors, additional trauma-specific services should be made available for consumers who wish to receive targeted treatment.

8. Building on empowerment-based trauma theories emphasizing the importance of actively participating in service programs and rebuilding a sense of control, programs should support and encourage consumer involvement. Examples of consumer involvement include active goal-setting and crisis planning, peerled services, leadership roles for consumers, and involvement in program design, evaluation, and refinement.

9. All trauma-informed services should be culturally and linguistically competent.

\section{Programming}

Our review of the theory, study, and practice of traumainformed services underscored six steps that are essential when implementing a trauma-informed model, including:

1. Obtaining "buy-in" at multiple levels within the system

2. Conducting a needs assessment to identify areas for change

3. Reviewing the organization's environment, procedures, and services and revising them to become more aligned with the principles of trauma-informed care

4. Providing training on trauma

5. Offering ongoing trauma-based consultation and supervision

6. Providing access to trauma-specific interventions

These principles and implementation strategies are a starting point for any program wishing to implement traumainformed services.
Beyond offering services that have a trauma-based framework, programming efforts are needed to establish agency-wide commitment to building trauma-informed services. Programming builds continuity among providers to establish the overall shift in program philosophy necessary for building trauma-informed services.

1. Homeless programs should integrate trauma awareness and responsiveness into their program missions.

2. There is a need to operationalize the principles of trauma-informed services, and to link these principles to quantitative, measurable changes that can be tracked and evaluated.

3. Guidelines should be developed for implementing a trauma-informed model or framework in homeless service settings.

4. Programs working for larger systems change towards a trauma-informed model should start with an organizational self-assessment in order to identify strengths and target areas for change.

5. Organizations should institute regular internal and/or external reviews to assess the degree to which their programs are trauma-informed.

6. Despite the fact that they work with trauma survivors on a daily basis, most staff members within homeless services are not trained about the impact of trauma or strategies for working with trauma survivors. Homeless services should implement standardized training on understanding traumatic stress and working with trauma survivors. Because these concepts are complex and cannot be adequately covered in one training, regular follow-up trainings should be offered.

7. A consultation model that is ongoing and responsive to specific needs should be utilized to reinforce concepts learned in trainings, as well as to help providers apply what they have learned to actual situations in their service settings.

8. Regular supervision should be offered in order to assist staff members in understanding the impact of trauma in particular situations, and to aid staff in recognizing and managing their own reactions.

9. Homeless services should design trauma-informed environments, including attention to issues of physical space, triggering materials, privacy/ confidentiality, and structure/ predictability.

10. Policies and protocols should be reviewed to ensure that they are consistent with a trauma-informed model and are not inadvertently retraumatizing.

11. Homeless service organizations should be aware of and responsive to issues of job stress, burnout, and vicarious trauma in providers. Programs need to have structures in place for prevention of, and early intervention for, vicarious trauma. In terms of prevention, it is recommended that organizations institute policies, programs, or activities that encourage staff self-care and support. 
12. Consumer involvement is an integral part of a traumainformed system. It is recommended that consumers of homeless services participate as active members in program development, operation, and evaluation. Some possibilities for this involvement include: Town Hall meetings, consumer advisory boards, and peerled groups. Prescott [22] offers guidelines for integrating consumers into trauma-informed programs.

13. Services and programs should promote cultural diversity and competency.

Policy

The evidence on trauma-informed services in homeless settings is limited and there is a lack of clearly defined principles, definitions, and methods for establishing traumainformed services. More research is needed to evaluate the process of developing trauma-informed services and to evaluate the effectiveness of trauma-informed services for homeless individuals. State and federal funding should be appropriated for examining evidence for trauma-informed interventions. The National Association of State Mental Health Program Directors (NASMHPD) has taken a first step in this direction by recommending that states establish financing criteria and mechanisms for funding best-practice trauma treatment models and services. However, these policy efforts should be expanded to include federal and local funding, and to include a focus on homeless service settings.

The current review of trauma-informed homeless services suggests a number of policies whose adoption is necessary to move the field further:

1. Policies should support homeless services that employ strategies to prevent trauma exposure, including the elimination of practices that are retraumatizing.

2. Policies should support increased capacity for early detection of trauma within homeless service settings.

3. Mainstream services should be available and accessible to individuals experiencing homelessness and should be responsive to the needs of trauma survivors.

4. Policies should guide the development and offering of comprehensive, integrated, trauma-informed treatment within homeless service settings.

5. Policies should prescribe and define consumer involvement in developing and evaluating homeless services.

6. Policies should ensure that funding is available to develop and sustain trauma-informed care.

7. Policies should ensure that services are designed to be developmentally-appropriate, and culturally and linguistically competent.

8. Trauma-informed homeless service policies need to be supported by larger systems guiding services for homeless individuals and families, including national, state, and local governmental, community-based groups, and non-profit organizations. Some of these systems include: the U.S. Department of Health and
Human Services, the U.S. Department of Veterans Affairs, the U.S. Departments of Housing and Urban Development, the U.S. Interagency Council on Homelessness, state-level councils to end homelessness, the National Alliance to End Homelessness, the National Health Care for the Homeless Council, the National Law Center on Homelessness and Poverty, the National Center on Family Homelessness, and the Homelessness Resource Center.

\section{Research}

There is a paucity of research examining the effectiveness of trauma-informed services for homeless individuals and families. Most programs that have begun to institute trauma-informed practices have not tested their models for effectiveness. This may be due to financial constraints and to the fact that many programs are focused on direct service, as opposed to research.

1. Although research on trauma-informed services in the mental health and substance use fields is promising, further research is needed on developing traumainformed services within homeless service settings.

2. Researchers and providers need to establish a greater consensus about what constitutes a "trauma-informed service system." Clearly defining what is meant by a "trauma-informed system" will create greater uniformity in research, increasing the ability to compare strategies for implementing trauma-informed systems.

3. Methods to achieve trauma-informed systems also need to be more clearly established. The conceptual framework established by a set of guiding principles should be behaviorally defined within a system. This allows fidelity measurements, indicating the degree to which a program is meeting the general standards for a trauma-informed program. Clearly defining methods will also lead to the possibility of a classification system delineating varying levels of trauma-informed systems.

4. Although a number of models or frameworks for building trauma-informed services have been developed, more evidence is needed to evaluate and refine these approaches. Thus, additional research is needed to evaluate trauma-informed models within homeless settings. It is recommended that additional research within the homelessness arena be conducted using models such as ARC, CARE, A Long Journey Home, Sanctuary, and Using Trauma Theory to Design Service Systems.

5. The corroborative evidence that is available offers a clear starting point for future research on traumainformed homeless services. Additional qualitative research is needed to more clearly define the process of offering trauma-informed services, while quantitative studies should follow after models have been clearly defined and described. These should examine the outcomes of trauma-informed interventions. 
6. Additional research is needed to distinguish the relative contribution of trauma-informed care, versus trauma-specific services. The majority of the research to date on trauma-informed care has also included trauma-specific services. While clinically this makes intuitive sense, research is needed to evaluate what specific factors are leading to change within these systems.

7. Additional research is required on the needs of special populations who are homeless. For instance, additional research is needed to determine how trauma-informed care should be adapted to meet the unique issues faced by youth, veterans, individuals from other countries, individuals of different ethnic backgrounds, and LGBT individuals who are experiencing homelessness.

Trauma-informed homeless services offer a promising new area for increasingly effective and sensitive service approaches for highly vulnerable people. Because many, if not all, homeless individuals have been exposed to high levels of traumatic stress, it is essential that homeless service systems develop sensitivity and responsiveness to posttrauma responses among the people they serve. More efforts are needed in terms of practice, programming, policy, and research to continue to build empirically-based, effective models of trauma-informed care for people who are struggling daily to exit homelessness.

\section{ACKNOWLEDGEMENTS}

Special thanks to Dawn Jahn-Moses of the National Center on Family Homelessness, and the team at the Center for Social Innovation.

\section{CONFLICT OF INTEREST}

Authors work within organizations that developed some of the models reviewed (e.g. organizational assessments, ARC model, Phoenix Rising).

This document was developed under Contract No. HHSS280200600029C from the Substance Abuse and Mental Health Services Administration (SAMHSA), U.S Department of Health and Human Services (HHS). The views, policies, and opinions expressed are those of the authors and do not necessarily reflect those of SAMHSA or HHS.

\section{APPENDIX 1}

\section{Traumatic Stress and Homelessness}

\begin{abstract}
"Homelessness deprives individuals of...basic needs, exposing them to risky, unpredictable environments. In short, homelessness is more than the absence of physical shelter, it is a stress-filled, dehumanizing, dangerous circumstance in which individuals are at high risk of being witness to or victims of a wide range of violent events" [1].
\end{abstract}

Researchers have documented that the rates of traumatic stress are extremely high, and may even be normative, among those experiencing homelessness. Individuals who are homeless may have been exposed to neglect, psychological abuse, physical abuse, or sexual abuse during childhood; community violence; sexual assault; combatrelated traumas; domestic violence; and accidents or disasters. A literature review found consistent and welldocumented evidence of high levels of multiple forms of traumatic stress within individuals and families who are homeless. It is clear that trauma affects people of every gender, age, race, sexual orientation, and background within homeless service settings. No one is immune. The following data highlight this point:

\section{Men}

- $\quad$ More than 2/3 of men in a dual-diagnosis treatment program for homeless people reported a history of trauma -- either physical or sexual abuse [28].

- $\quad$ More than 1/4 of homeless men were assaulted in the past year [56].

- Homeless men within substance treatment programs have a high prevalence of depression, family dysfunction, trauma, and multiple previous treatment experiences [57].

- Despite the fact that men comprise the majority of homeless people and are frequently exposed to trauma, homeless men are less likely to receive social services than homeless women [58], with less effort directed towards understanding the impact of trauma for this population.

\section{Women/Mothers}

- Although many people think of men when they consider the issue of homelessness, familiestypically single mothers with young children-now comprise up to $40 \%$ of the overall homeless population [59].

- $\quad$ Trauma is extremely prevalent among homeless women: over $90 \%$ of homeless mothers report having experienced severe physical or sexual assault during their lifetimes [60].

- The majority of homeless mothers were abused during childhood, with nearly $2 / 3$ reporting severe physical abuse and $42 \%$ reporting sexual abuse; $60 \%$ were abused before the age of twelve [2].

- More than $70 \%$ of homeless mothers have at least one childhood risk factor, including: severe physical abuse, unwanted sexual contact, having a parent who was mentally ill or who abused substances, running away for a week or more, or being in foster care [61].

- Homeless mothers are also frequently the victims of abuse during adulthood, with $61 \%$ reporting a history of domestic violence and 32\% acknowledging recent domestic violence [2].

- Homelessness puts women at risk for assault; being homeless was associated with more than three times the risk of sexual assault for women [56].

- Homelessness and victimization are associated with adverse mental health outcomes: more than $50 \%$ of homeless mothers reported depression, and more than $40 \%$ reported posttraumatic stress disorder (PTSD) 
[62], and were three times as likely as housed women to suffer from PTSD [63].

\section{Children and Youth}

- $\quad$ Child abuse is associated with high-risk behaviors in adolescents, such as truancy and running away, that may lead to homelessness [64]. Almost 3/4 of girls on the streets report that they were forced to run away from violence at home [65].

- Homeless children and youth are at risk for further victimization, such as repeated abuse, exposure to violence, and forced prostitution [66].

- $86 \%$ of homeless youth report exposure to trauma, with almost $2 / 3$ reporting exposure to multiple traumatic events; physical assaults are prevalent for young men, while sexual/physical abuse is common among young women [67].

- Homeless children are at increased risk for medical, emotional, behavioral, and academic problems, including post-trauma responses, insecure attachments, and difficulty learning [60, 68, 69].

\section{Elderly}

- $\quad$ The elderly make up a relatively lower percentage of the homeless population, only 2\% [70]; however, elderly homeless persons are more vulnerable to victimization, have more health problems, and may be less likely to receive needed social services and protection from law enforcement [71].

- In $2006,27 \%$ of the homeless victims of violent crimes were between 50-59 years of age [9].

\section{Veterans}

- Veterans are disproportionately represented in the homeless population, with veterans making up 23\% of all homeless people in the U.S. [72].

- $\quad$ The majority of women in homeless veteran programs have serious trauma histories, including being physically harassed, sexually harassed, or raped while in the military [73].

- One-quarter or more of homeless veterans manifest symptoms of PTSD; 76\% experience alcohol, drug, or mental health problems [74].

- $\quad$ Trauma and related distress are related to relapse and rehospitalization of homeless veterans who have substance abuse problems, particularly for female veterans [75].

\section{Minorities}

- $\quad$ Minorities are over-represented among the homeless population, with almost half being African-American [4].

- Families of color also disproportionately experience trauma [50].

Lesbian, Gay, Bisexual, \& Transgendered (LGBT) Individuals

- $\quad 40 \%$ of homeless youth identify as LGBT.
- One-third of LGBT youth are assaulted after disclosing their sexual orientation; $40 \%$ to $60 \%$ of homeless youth cited physical abuse as a reason for leaving home [76].

- Thirty-three percent of transgendered individuals reported that they had been physically or sexually assaulted in the past year [56].

These statistics suggest that it is reasonable to assume that the majority of homeless individuals have been exposed to traumatic stress. Most people experiencing homelessness have been victimized one or more times in their lives. For many people, abuse began during childhood; in fact, developmental trauma with disrupted attachments may provide the subtext for the stories of many people's pathways towards homelessness [2]. Violence continues into adulthood for many people, with abuse such as domestic violence often precipitating homelessness [3-5], and with homelessness leaving people vulnerable to further victimization. In fact, homelessness has been suggested to be a traumatic event in and of it, compounding the psychological impact of the myriad risk factors often experienced by people who are homeless [77]. Based on this assumption, we can conclude that individuals experiencing homelessness are, by definition, trauma survivors, demonstrating the urgency of addressing trauma within this population.

Another reason that it is important to address trauma within homelessness service settings is that victimization is associated with repeated episodes of homelessness. Research has found that people who experienced repeated homelessness were more likely than people with a single episode of homelessness to have been abused, often during childhood. First-time homeless mothers who experienced domestic violence were more than three times as likely to become homeless again [6]. These findings suggest that we will be unable to solve the issue of homelessness without addressing the underlying trauma that is so intricately interwoven with the experience of homelessness.

As can be seen from this description, the relationship between trauma and homelessness is complex, with traumatic stress being a possible core factor increasing vulnerability to homelessness, and with homelessness leaving individuals more vulnerable to further victimization. There is also a complex and multi-directional relationship between trauma, substance abuse, mental illness, and homelessness. All these factors need to be addressed in services for homeless men, women, children and youth, the elderly, minorities, veterans, LGBT individuals, and other people.

\section{APPENDIX 2}

\section{The Impact of Trauma}

Traumatic stress can be devastating and long-lasting. To develop an understanding about how to build traumasensitive services, we need to first clearly understand that the impact of traumatic stress can be devastating and longlasting, interfering with a person's sense of self, and sense of safety, leading to feelings of helplessness, terror, and disempowerment. Traumatic exposure may lead to responses 
Table 3. How Common Trauma Reactions May Explain Some "Difficult" Behaviors or Reactions Within Homeless Service Settings

"Difficult" Behaviors or Reactions within Homeless Service Settings

Common Trauma Reactions

Has difficulty getting motivated to get job training, pursue education, locate a job, or find housing Depression and diminished interest in everyday activities

Complains that the setting is not comfortable or not safe, appears tired and poorly rested. Is up

roaming around at night.

Perceives others as being abusive, loses touch with current-day reality and feels like the trauma is happening over again

Avoids meetings with counselors or other support staff, emotionally shuts down when faced with traumatic reminders

Isolates within the shelter, stays away from other residents and staff

Lacks awareness of emotional responses, does not emotionally respond to others

Feeling detached from others

Is alert for signs of danger, appears to be tense and nervous

Emotional numbing or restricted range of feelings

Has interpersonal conflicts within the shelter, appears agitated

Hyper-alertness or hypervigilance

Has difficulty keeping up in educational settings or job training programs

Irritability, restlessness, outbursts of anger or rage

Becomes agitated within the shelter. Is triggered by rules and consequences. Has difficulty setting limits with children.

Difficulty concentrating or remembering

Has difficulty following rules and guidelines within the shelter or in other settings. Is triggered

when dealing with authorities. Will not accept help from others.

Feeling unsafe, helpless, and out of control

Feels emotionally "out of control." Staff and other residents become frustrated by not being able to Affect dysregulation (emotional swings - like crying and predict how he or she will respond emotionally then laughing)

Seems spacey or "out of it." Has difficulty remembering whether or not they have done something

Is not responsive to external situations.

Dissociation

Complains of aches and pains like headaches, stomachaches, backaches. Becomes ill frequently.

Cuts off from family, friends, and other sources of support

Psychosomatic symptoms, impaired immune system

Has difficulty trusting staff members; feels targeted by others. Does not form close relationships in the service setting.

Complains that the system is unfair, that they are being targeted or unfairly blamed

Feelings of shame and self-blame

Puts less effort into trying--does not follow through on appointments, does not respond to

assistance

Difficulty trusting and/or feelings of betrayal

Invades others' personal space or lacks awareness of when others are invading their personal space Boundary issues

Has ongoing substance abuse problems

Use of alcohol or drugs to manage emotional responses

Remains in an abusive relationship or is victimized again and again

Revictimization (impaired ability to identify danger signs)

including Posttraumatic Stress Disorder (PTSD) and Complex Trauma.

Posttraumatic Stress Disorder (PTSD) refers to a group of symptoms that some individuals experience after overwhelming, frightening, or horrifying life experiences that exceed their capacity to cope. PTSD includes intrusive symptoms such as triggered memories or nightmares, avoidance symptoms such as social withdrawal, constriction, and emotional numbing, and symptoms of hyperarousal such as concentration problems, irritability, and constant alertness for danger.

Exposure to chronic interpersonal trauma such as child abuse or domestic violence may have an even more extensive impact on the survivor, sometimes referred to as "Complex PTSD," or "Disorders of Extreme Stress, Not Otherwise Specified" (DES-NOS). Survivors with Complex PTSD have difficulty regulating their internal states, including their emotional states and their physiological reactions. Their emotions sometimes shift rapidly, leaving them feeling helpless in the face of overwhelming emotion. Their bodies are easily activated, resulting in anxiety, panic, or terror. At other times, they have dissociative responses in which their bodies or emotions shut down and they become numb. Triggered responses, reactions to reminders of the trauma, are also common. In Complex PTSD, the traumatic experiences impact the survivor's sense of self; survivors often blame themselves for their abuse, feeling damaged and ashamed. Individuals who have experienced chronic interpersonal trauma often have problems sustaining supportive relationships, such as difficulty trusting others or problems establishing clear boundaries and setting limits with others. This increases their vulnerability to retraumatization, and interferes with the development of adequate social networks for support in times of crisis. Individuals with Complex PTSD may have impaired 
immune system functioning and may experience poor physical health. They often have difficulty maintaining attention and concentration and may have memory problems. Their belief systems about the world are also altered and they often feel unsafe [78-80].

In describing the link between trauma exposure and homelessness, Browne [2] wrote, "it seems probable that, for some homeless women, the effects of early violence or molestation by intimates decreased their supportive networks and increased their risk of becoming homeless later in life." Thus, exposure to traumatic stress may increase people's vulnerability to becoming homeless in certain situations, and conversely, traumatic stress reactions may make it more difficult to cope with the stresses inherent in being homeless.

Homeless service providers who lack a basic knowledge of trauma will not have a context for understanding traumabased reactions. Table 3 illustrates behaviors sometimes seen in homeless service settings that can be confusing or frustrating for providers or other consumers; column two of the chart demonstrates how each of these behaviors may be explained in the context of common reactions to traumatic stress. This chart highlights the need for understanding trauma within homeless service settings.

\section{REFERENCES}

[1] Fitzpatrick KM, LaGory ME, Ritchey FJ. Dangerous places: Exposure to violence and its mental health consequences for the homeless. Am J Orthopsychiatry 1999; 69: 438-47.

[2] Browne A. Family violence and homelessness: The relevance of trauma histories in the lives of homeless women. Am J Orthopsychiatry 1993; 63: 370 .

[3] National Law Center on Homelessness and Poverty. Some facts on homelessness, housing, and violence against women 2006.

[4] US Conference of Mayors. Hunger and homelessness survey: A status report on hunger and homelessness in America's cities 2005.

[5] Zorza J. Women battering: a major cause of homelessness. Clgh Rev 1991; 25: 412-29.

[6] Bassuk EL, Perloff JN, Dawson R. Multiply homeless families: The insidious impact of violence. Hous Policy Debates 2001; 12: 299-320.

[7] Fischer PJ, Breakey WR. The Epidemiology of Alcohol, Drug, and Mental-Disorders among Homeless Persons. Am Psychol 1991; 46: 1115-28.

[8] Jainchill N, Hawke J, Yagelka J. Gender, psychopathology, and patterns of homelessness among clients in shelter-based TCs. Am J Drug Alcohol Abuse 2000; 26: 553-67.

[9] National Coalition for the Homeless. Hate, violence, and death on Main Street USA: a report on hate crimes and violence against people experiencing homelessness 2006.

[10] SAMHSA's National Mental Health Information Center. Homelessness 2007.

[11] Goodman LA, Dutton MA, Harris M. Episodically homeless women with serious mental-illness - prevalence of physical and sexual assault. Am J Orthopsychiatry 1995; 65: 468-78.

[12] Harris M, Fallot RD. New directions for mental health services: Using trauma theory to design service systems. San Francisco: Jossey-Bass 2001.

[13] Moses DJ, Reed BG, Mazelis R. Creating trauma services for women with co-occurring disorders: experiences from the SAMHSA women with alcohol, drug abuse, and mental health disorders who have histories of violence study. Delmar, NY: Policy Research Associates, Inc. 2003.

[14] Elliott DE, Bjelajac P, Fallor RD. Trauma-informed or trauma-denied: Principles and implementation of trauma-informed services for women. J Commun Psychol 2005; 33: 461-77.

[15] Olivet J, Bassuk E. Evidence-based practices in homeless services: An issue brief. Rockville: Center for Mental Health Services 2007.

[16] Morrissey JP, Jackson EW, Ellis AR. Twelve-month outcomes of trauma-informed interventions for women with co-occurring disorders. Psychiatr Serv 2005; 56: 1213-22.
[17] Stainbrook KA, Hornik J. Similarities in the characteristics and needs of women with children in homeless family and domestic violence shelters. Fam Soc 2006; 87: 53-62.

[18] Warshaw C, Moroney G. Mental health and domestic violence: Collaborative initiatives, service models, and curricula. Chicago: Domestic Violence and Mental Health Policy Initiative 2002.

[19] Moses DJ, Huntington N, D'Ambrosio B. Developing integrated services for women with co-occurring disorders and trauma histories: Lessons from the SAMHSA women with alcohol, drug abuse, and mental health disorders who have histories of violence study. Delmar, NY: Policy Research Associates, Inc. 2004.

[20] Young HE, Rosen CS, Finney JW. A survey of PTSD screening and referral practices in VA addiction treatment programs. J Subst Abuse Treat 2005; 28: 313-9.

[21] Padgett DK, Hawkins LR, Abrams C. In their own words: Trauma and substance abuse in the lives of formerly homeless women with serious mental illness. Am J Orthopsychiatry 2006; 76: 461-7.

[22] Prescott L. Consumer/survivor/recovering women: A guide for partnerships in collaboration. Delmar, NY: Policy Research Associates, Inc. 2001.

[23] Rog DJ, Holupka CS, Mccombsthornton KL. Implementation of the Homeless Families Program.1. Service Models and Preliminary Outcomes. Am J Orthopsychiatry 1995; 65: 502-13.

[24] Prochaska JO, DiClemente CC. Stages and process of self-change of smoking: Toward an integrative model of change. J Consult Clin Psychol 1983; 51:390-5.

[25] Community Connections. Final report: Trauma-informed pilot project at the Rumford (Maine) unit of tri-county mental health services 2003.

[26] Veysey B, Heckman K, Mazelis R. It's my time to live: Journeys to healing and recovery. Rockville, MD: Substance Abuse and Mental Helalth Services Administration 2007.

[27] Mockus S, Cinq Mars L, Guazzo Ovard D. Developing consumer/survivor/recovering voice and its impact on services and outreach: Our experiences with the SAMHSA women, co-occurring disorders and violence study. J Commun Psychol 2005; 33: 513-25.

[28] Christensen RC, Hodgkins CC, Garces LK. Homeless, mentally ill and addicted: The need for abuse and trauma services. J Health Care Poor Underserved 2005; 16: 615-21.

[29] McHugo GJ, Caspi Y, Kammerer N. The assessment of trauma history in women with co-occurring substance abuse and mental disorders and a history of interpersonal violence. J Behav Health Serv Res 2005; 32: 113-27.

[30] Marra JV. Final evaluation report: Evaluation of the trauma center of excellence initiative. Unpublished program evaluation. Storrs, CT: University of Connecticut Department of Psychology and the CT Department of Mental Health and Addiction Services Research Division 2006.

[31] Cocozza JJ, Jackson EW, Hennigan K. Outcomes for women with cooccurring disorders and trauma: Program-level effects. J Subst Abuse Treat 2005; 28: 109-19.

[32] Finkelstein N, Rechberger E, Russell LA. Building resilience in children of mothers who have co-occurring disorders and histories of violence: Intervention model and implementation issues. J Behav Health Serv Res 2005; 32: 141-54.

[33] Bloom S. Organizational stress as a barrier to trauma-sensitive change and system transformation. Alexaandria, VA: National Technical Assistance Center for State Mental Health Planning Pulications and Reports 2006.

[34] McCabe S, Unzicker RE. Changing roles of consumer/survivors in mature mental health systems. New Dir Ment Health Serv 1995; 66: 6173.

[35] National Association of State Mental Health Program Directors. Position statement on services and supports to trauma survivors 1998.

[36] Zimmerman MA. Toward a theory of learned hopefulness - a structural model analysis of participation and empowerment. J Res Pers 1990; 24 : 71-86.

[37] Morrissey JP, Ellis AR, Gatz M. Outcomes for women with cooccurring disorders and trauma: Program and person-level effects. J Subst Abuse Treat 2005; 28: 121-33.

[38] Kammerer N. Project RISE evaluation report. Unpublished program evaluation report. Boston, MA: Heatlh and Addictions Research, Inc. and Health Institute for Recovery n.d.

[39] Noether CD, Brown V, Finkelstein N. Promoting resiliency in children of mothers with co-occurring disorders and histories of trauma: Impact of a skills-based intervention program on child outcomes. J Commun Psychol 2007; 35: 823-43. 
[40] Community Connections. Trauma and abuse in the loves of homeless men and women. Online PowerPoint presentation. Washington, DC 2002. Available from: http:/www.pathprogram.samhsa.gov/ppt/ TraumaVandVHHomelessness.ppt

[41] Domino ME, Morrissey JP, Chung S, Huntington N, Larson MJ, Russell LA. Service use and costs for women with co-occurring mental and substance use disorders and a history of violence. Psychiatr Serv 2005; 56: 1223-32.

[42] Jennings A. The damaging consequences of violence and trauma: facts, discussion points, and recommendations for the behavioral health system. Alexandria, VA: National Association of State Mental Health Program Directors, National Technical Assistance Center for State Mental Health Plannin 2004.

[43] Kinniburgh KJ, Blaustein M, Spinazzola J. Attachment, self-regulation, and competency. Psychiatr Ann 2005; 35: 424-430.

[44] Prescott L, Soares P, Konnath K, Bassuk E. A long journey home: a guide for creating trauma-informed services for homeless mothers and children. Rockville, MD: Center for Mental Health Services, Substance Abuse and Mental Health Services Administration 2007.

[45] Youth on Fire, Trauma Center at JRI. Phoenix rising: a traumainformed approach to HIV/substance use/hepatitis prevention for homeless and street-involved youth. 2007.

[46] Bloom S. Creating sanctuary: Toward the evolution of sane societies. New York: Routledge 1997.

[47] National Child Traumatic Stress Network. National child traumatic stress network empirically supported treatments and promising practices 2007.

[48] Kinniburgh K, Blaustein M. ARC: Attachment, regulation, \& competency. A comprehensive framework for intervention with complexly traumatized youth. Brookline, MA: The Trauma Center at Justice Resource Institute 2005.

[49] Hopper E, Spinazzola J. Trauma-informed facility assessment. Brookline, MA: The Trauma Center at Justice Resource Institute 2006.

[50] Guarino K, Soares P, Konnath K. Trauma-informed organizational selfassessment for programs serving families experiencing homelessness. Rockville, MD: Center for Mental Health Services, Substance Abuse and Mental Health Services Administration 2007.

[51] Fallot RD, Harris M. Trauma-informed services: a self-assessment and planning protocol. Community Connections 2002.

[52] Institute for Health and Recovery. Developing trauma-informed organizations: a toolkit 2002.

[53] Reinis T. New direction: 15 years of service to veterans. Testimony of Toni Reinis 2007.

[54] Jennings A. Models for developing trauma-informed behavioral health systems and trauma-specific services. Alexandria, VA: National Association of State Mental Health Program Directors, National Technical Assistance Center for State Mental Health Planning 2004.

[55] SAMHSA Homeless Families Coordinating Center. Trauma interventions for homeless families - Innovative features and common themes 2005 .

[56] Kushel MB, Evans JL, Perry S, Robertson MJ, Moss AR. No door to lock - Victimization among homeless and marginally housed persons. Arch Intern Med 2003; 163: 2492-9.

[57] Kim M, Roberts A. Exploring trauma among homeless men in treatment for substance abuse: a qualitative approach. J Soc Work Pract Addict 2004; 4: 21-32.

[58] Calsyn RJ, Morse G. Homeless men and women: Commonalities and a service gap. Am J Commun Psychol 1990; 18: 597-608.
[59] Guarino K, Rubin L, Bassuk E. Trauma in the lives of homeless families. In: Carll EK, Ed. Trauma psychology: Issues in violence, disaster, health and illness. Westport, CT, Praeger Publishers 2007; pp. 231-58.

[60] Bassuk EL, Weinreb L. The characteristics and needs of sheltered homeless and low-income housed mothers. JAMA 1996; 276: 640.

[61] Rog DJ, Mccombsthornton KL, Gilbertmongelli AM. Implementation of the Homeless Families Program. 2. Characteristics, strengths, and needs of participant families. Am J Orthopsychiatry 1995; 65: 514-28.

[62] Weinreb L, Buckner JC, Williams V. A comparison of homeless mothers in Worcester, MA: 1993 vs 2003. Am J Public Health 2006; 96: 1444-8.

[63] Bassuk EL, Buckner JC, Perloff J. Prevalence of mental health and substance abuse disorders among homeless and low-income housed mothers. Am J Psychiatry 1998; 155: 1561-4.

[64] Briere JN. Child abuse trauma. Newbury Park, CA: Sage Publications 1992.

[65] Chesney-Lind M, Sheldon RG. Girls, delinquency, and juvenile justice. Belmont, CA: Wadsworth 1998.

[66] Whitbeck LB, Hoyt DR, Yoder KA. A risk-amplification model of victimization and depressive symptoms among runaway and homeless adolescents. Am J Commun Psychol 1999; 27: 273-96.

[67] Gwadz MV, Nish D, Leonard NR. Gender differences in traumatic events and rates of post-traumatic stress disorder among homeless youth. J Adolesc 2007; 30: 117-29.

[68] Buckner JC, Beardslee WR, Bassuk EL. Exposure to violence and lowincome children's mental health: Direct, moderated, and mediated relations. Am J Orthopsychiatry 2004; 74: 413-23.

[69] Cowal K, Shinn M, Weitzman BC. Mother-child separations among homeless and housed families receiving public assistance in New York City. Am J Commun Psychol 2002; 30: 711.

[70] US Department of Housing and Urban Development. Ann homeless assessment report to Congress 2007.

[71] National Coalition for the Homeless. Homelessness among elderly persons. NCH Fact Sheet \#15 2007.

[72] National Coalition for the Homeless. Homeless Veterans. NCH Fact Sheet \#14 2007.

[73] National Coalition for Homeless Veterans. Background and statistics: Most often asked questions concerning homeless veterans 2005.

[74] McMurray-Avila M. Homeless veterans and health care: a guide for providers. Nashville: Health Care for the Homeless Council 2001.

[75] Benda BB. Survival analyses of social support and trauma among homeless male and female veterans who abuse substances. Am J Orthopsychiatry 2006; 76: 70-79.

[76] Ray N. Lesbian, gay, bisexual and transgender: an epidemic of homelessness 2006.

[77] Goodman L, Saxe L, Harvey M. Homelessness as psychological trauma - broadening perspectives. Am Psychol 1991; 46: 1219-25.

[78] Luxenburg T, Spinazzola J, Hidalgo J. Complex trauma and disorders of extreme stress (DESNOS) diagnosis, part II: Treatment. Dir Psychiatry 2001; 21: 395-415.

[79] Luxenburg T, Spinazzola J, van der Kolk BA. Complex trauma and disorders of extreme stress (DESNOS) diagnosis, part I: Assessment. Dir Psychiatry 2001; 21: 373-93.

[80] van der Kolk BA, McFarlane AC, Weisaeth L. Traumatic stress. New York: Guilford Press 1996. 